\title{
A REDEFINIÇÃO CONTINUADA DO LUGAR DA CANÇÃO POPULAR NA CULTURA BRASILEIRA CONTEMPORÂNEA
}

\author{
Sylvia H. Cyntrão ${ }^{1}$
}

\begin{abstract}
Resumo: Este texto propõe-se a discutir a continuidade sempre redefinida da canção popular brasileira a partir da década dos anos 60 do século XX e de que forma manifestase contemporaneamente como vetor estético de representação, sendo um produto cultural que trabalha com a transfiguração do real, manipulando um capital simbólico coletivo. Entende-se seu criador como o sujeito que ressignifica esteticamente as tradições culturais. Este artigo tenta oferecer algumas pistas sobre o lugar social e existencial do cancionista hoje, no Brasil.
\end{abstract}

Palavras-Chave: Cultura. Imaginário. Canção contemporânea

Entende-se a canção como um gênero artístico híbrido de duas séries ou sistemas sígnicos de base - o literário e o musical -, vetor estético de representação existencial, produto cultural que trabalha com a transfiguração do real, na tradução continuada de um capital simbólico coletivo. A Música Popular Brasileira a que nos referimos não é apenas a do segmento MPB, pós Bossa Nova, a dos Festivais das décadas de 1960 e 1970, mas aquela mais ampla a que vamos aqui chamar de canção popular, tida como uma forma de representação urbana e de expressão que faz convergir ao espetáculo texto, melodia e também a sua performance.

Dominique Maingueneau (1998) com o conceito de paratopia nos remete à discussão sobre a multiplicidade da expressão poética contemporânea e nesse conjunto pode-se incluir a letra das canções. Ele aponta para o fato de a literatura ser um espaço diferente das outras atividades sociais, porque não é possível definir para ela um espaço estável no âmbito da sociedade. Esse é o ponto de partida, então, para a negociação entre lugar e não-lugar. O que se fala se fala de onde? Como característica típica deste tempo, a contemporaneidade, os estilos particulares e hiper-individuais são a regra.

Postulo aqui uma leitura com foco sobre a intentio lectoris (conceito de Umberto Eco que agrega duas outras 'intentio', a auctoris e a operis prevendo o conjunto de manifestações que convergem para a produção e o entendimento de uma obra) Esta se justifica quando nos entendemos como destinatários historicamente situados, com referenciais culturais e psicológicos que promovem reflexões significativas sobre o sujeito contemporaneamente situado no espaço da nação brasileira, na eleição das letras da MPB como objeto de análise do simbólico que constitui o imaginário coletivo.

Segundo Bhabha (2005) "Cada objetivo [interpretativo] é construído sobre o traço daquela perspectiva que ele rasura; cada objeto político é determinado em relação ao outro e deslocado no mesmo ato crítico". Passa-se assim a ler nos textos as diferenças culturais processos de enunciação da cultura - que, ainda segundo o crítico, são "processos de

\footnotetext{
1 Doutora em Literatura brasileira. Pós-doutorado (PUC-RJ). Universidade de Brasília/Instituto de Letras/Departamento de Teoria Literária e Literaturas. E-mail: cyntrao@unb.br.

Lattes: http://lattes.cnpq.br/2907523784331163.
} 
significação através do qual afirmações da cultura ou sobre a cultura diferenciam, discriminam e autorizam a produção de campos de força...".

Aproveitando este e outro de seus conceitos, situo o cancionista contemporâneo no que ele chama de entre-lugar, que é o espaço estético de intervenção em que qualquer identidade radical é diluída e o sujeito artístico é livre para ressignificar o imaginário que o inspira a falar. A canção popular apresenta-se nesse sentido como um sistema de significações para o qual convergem e de onde partem sentidos sociológicos e culturais de um modo de vida urbano geracional. A globalização a partir dos anos de 1990 modificou a relação entre arte e realidade quando instaurou novos paradigmas na aproximação de linguagens diversificadas, com a consequente geração de formas cada vez mais híbridas, tanto as reprodutoras das estruturas dominantes, bem como as desarticuladoras e críticas do sistema sócio-político-econômico mundial.

Lembremos que o sujeito da pós-modernidade (este tempo presentificado dos fins do século XX em diante) segundo Stuart Hall (1998), não tem uma identidade fixa, permanente. É a metamorfose ambulante (expressão de nosso cancionista Raul Seixas), podendo ser deslocada dependendo de seu próprio interesse. Nesse sentido, os artistas contemporâneos parecem incorporar essa mutação deslizante.

Assim, as práticas artísticas da pós-modernidade transitam nos limites de hibridação dos gêneros e os sistemas semióticos concorrem, dessa forma, para a sua fabricação. Isso é patente. Basta irmos a qualquer apresentação em bienais, a festivais de música, a museus interativos, a espaços públicos ou em casas de show que haverá imagens visuais, texto em diálogo com som, projeções de vídeos, entre outros elementos que se agregaram à expressão musical popular. Podemos dizer que vêm apresentando um processo de hibridação progressivo, gerado pela erosão de fronteiras entre os gêneros (mídia, canção, teatro).

As sociedades, como a brasileira, que tiveram um passado colonial, absorveram elementos sociais, psicológicos, étnicos, éticos e estéticos de outras civilizações, incorporando-os aos elementos nativos e desenvolvendo, nas gerações que se sucederam, uma identidade composta de multi-faces, multi-linguagens e multi-mitos, de sentido caracteristicamente deslizante. A coexistência de vários discursos em diferentes registros alia-se à diversificação dos temas abordados nas produções musicais, emersos da diversidade cultural.

No caso da canção brasileira, destaca-se a longevidade qualitativa da voz lírica de Chico Buarque de Hollanda, cuja produção contínua ocupa ao menos 40 anos de nossa história. É de 1974 o lançamento do disco Sinal Fechado, um marco na discografia da MPB, em que o compositor, restrito pela censura do regime autoritário militar, assina apenas uma das canções, 'Jorge Maravilha' (ainda assim com o pseudônimo de Julinho da Adelaide) sendo as outras de artistas convidados, como Paulinho da Viola que assina a canção que deu o significativo título ao disco. Segundo Silva (2013) sendo a voz nacional uma voz identitária ela não estaria constituída em si mesma como uma subjetividade participante do coro lírico. Sendo vista como uma construção desse coro, teria que ser reconstituída criticamente a partir do substrato sociocultural e histórico inerentes às vozes que integram o fluxo semiotizante da lírica buarqueana. 
Vinculando a produção da MPB, da Poesia Marginal e das Vanguardas ao projeto poético brasileiro, Anazildo Silva (2013) apresenta a ideia que, a partir dele, ratifico:

\begin{abstract}
(...) pugnava não apenas pela legitimação dessa geração como um todo, mas também pelo reconhecimento e a integração de uma produção poética que estava aparentemente apartada da série literária. Expressava a opinião, defendida durante esses anos todos, de que a avaliação da produção poética da geração de 1960, dentro e fora da MPB, tinha de ser feita no âmbito da Literatura Brasileira, de acordo com os padrões críticos que definem a evolução das formas literárias, e não apenas no contexto paraliterário. E é com satisfação que constato a incorporação definitiva dessa postura crítica à nossa historiografia literária, comprovada na farta bibliografia, incluindo teses, antologias, songbook, ensaios críticos e históricos, além da inclusão da MPB nos livros didáticos de ensino de segundo e terceiro graus, efetivando, assim, a integração de toda a produção poética da geração 1960 no curso da lírica nacional.
\end{abstract}

Outras formas de expressão musical como o BRrock dos anos de 1980, os protestos do RAP, o movimento Mangue Beat de Chico Science, as canções sertanejas, o axé baiano, os sambas dos pagodes cariocas vão formar um conjunto plural, expressão de um fenômeno cultural chamado "dissemiNação", conceito bastante significante de Homi Bhabha- que explica a expressão simultânea de múltiplas subjetividades partindo de variados centros, dentro de um mesmo espaço geográfico.

Desde os anos de 1920 até os anos de 1960 o samba foi o estilo central do gênero canção no Brasil, mas no final dos anos de 1960, esse gênero dominante entrou em processo de descentramento, ou de "dissemiNação", quando a partir da Bossa Nova, com suas estruturas melódicas sofisticadas e seus temas do cotidiano da classe média, configurou-se uma crise de expressão que culminou com o movimento sincrético inaugural da estética pós-moderna na canção brasileira que foi o Tropicalismo.

Com esses novos cancionistas houve uma nova abordagem, inclusive ideológica, dos processos de expressão da realidade brasileira, como mostram, por exemplo, as imagens presentes na letra alegórica da canção "Tropicália" -uma alegoria da própria MPB. Caetano Veloso monta um mosaico nacional do momento histórico a partir de pares compostos de referências ao presente e ao passado nacionais: "Viva Iracema/Viva Ipanema/ (...) eu oriento o carnaval/eu inauguro o monumento no planalto central/do país/viva a bossa/viva a palhoça (...); viva a Banda /Carmem Miranda-da-da-da...".

Já na década de 1980 adentra o chamado BRock (Dapieve, 1986) com a expressão de Renato Russo, Cazuza e Arnaldo Antunes, que com suas bandas plugadas amplificaram a estética da canção, das interpretações e das questões temáticas, mantendo-se a acidez das críticas sociais, bastando lembrar algumas das letras mais entoadas pelo público como 'Brasil' de Cazuza e "Que país é este" de Renato Russo. Chega-se aos anos de 1990, em que os dois maiores porta-vozes da realidade existencial dessa década são acometidos pelo vírus do HIV e morrem, assumindo posições opostas sobre sua tragédia pessoal. De um lado, temos Cazuza afirmativamente mergulhado na sociedade do espetáculo expondo suas crises e, de outro, Renato Russo negando a espetacularização de seu estado terminal. 
Paralelamente ao rock brasileiro vinha sendo desenvolvido o chamado Movimento Mangue, oriundo da periferia do Recife (estado de Pernambuco, fora, portanto, do eixo midiático Rio-São Paulo) que emite um manifesto centrado na ressignificação da tradição da cultura musical brasileira. Esse movimento cultural que se originou das margens, lança suas letras que cantam realidades localizadas, mas antenadas com o contexto internacional (a 'parabólica enfiada na lama', expressão que consta do Manifesto Mangue escrito por Fred Zero 4).

A MPB de linha lírico-social do Mangue beat, tida como parte do projeto poético do Modernismo, tem na proposta antropofágica de Oswald de Andrade sua base de representação artística na hibridação de elementos regionais-étnicos (maracatu, xaxado e outros) com a música negra norte-americana de periferia, de inspiração no canto falado do rap.

Chico Science, o ícone do movimento, precocemente morto por um acidente automobilístico no auge de sua voz, na canção "Etnia" lança uma afirmativa centrada na idéia coletiva: "somos todos juntos uma miscigenação", "o seu e o meu são iguais/...samba que sai da favela acabada/ é hip hop na minha embolada", versos que remetem a elementos tradicionais da cultura brasileira, e à diluição das fronteiras culturais, como a referência ao hip hop. As canções do Mangue mostram, assim, a resistência e o valor dos elementos particulares convivendo com elementos da cultura estrangeira, criando uma zona de interfaces afirmativas.

É importante fazer referência à canção "Inclassificáveis" de Arnaldo Antunes, da mesma década de 1990, cuja letra aborda o mesmo tema, mas partindo de um outro lugar de fala: o do artista do eixo nacional do sudeste. A letra remete à questão da miscigenação nacional, a partir das referências significantes da linguagem. As perguntas iniciais " que preto, que branco, que índio o quê? /que branco, que índio, que preto o quê?"... levam à seqüência de compostos que representam as etnias formadoras da nacionalidade brasileira e registram a pluralidade coletiva do "somos": " aqui somos/ mestiços mulatos/(...)ameriquilatos/ luso nipo caboclos/" e muitas outras possibilidades mais, como "iberibárbaros indo ciganagôs...". Essas novas metabolizações criadas pelo texto resultam na constatação final: "crilouros guaranisseis e judárabes/(...) somos o que somos/inclassificáveis".

Antunes resume no vocábulo inclassificáveis o impasse contemporâneo criado pela rejeição do racionalismo centralista que "classifica", o que remete a outra letra de Science, em "Da lama ao caos" de 1994: “(...) comecei a pensar/ que eu me organizando posso me desorganizar/que eu desorganizando/ posso me organizar." É essa consciência da necessidade de ressignificação da tradição, a partir de um processo de subjetivação cultural inclusivo, que Science apresenta nos versos de "Etnia", quando aproxima manifestações diferenciadas compondo um mesmo sintagma, e referencia a miscigenação: "Maracatu psicodélico/(...)/Bumba meu rádio/Berimbau elétrico/Frevo,samba e cores/Cores unidas e alegria/ Nada de errado em nossa etnia."

A representação artística de Caetano na década de 1970, de Chico Science e Arnaldo Antunes, a partir dos anos de 1990, apresentou uma consciente hibridação, em oposição à homogeneização unitária da primeira metade do século XX. A canção incorpora o grito, a fala sem melodia, a voz performática e faz a defesa da mistura que 
acaba por figurar uma nação descentralizada, permeada pelo mais radicalmente local como pelo mais radicalmente global. As letras mencionadas propiciaram um espaço de discursos plurais e ideologicamente inclusivos.

Sobre essas novas relações de poder, há uma questão social decorrente que eu queria ressaltar, que é a consequência dessas identidades deslizantes e continuamente deslocadas. Voltamo-nos para a canção "Subúrbio" (do CD Carioca, 2006), de Chico Buarque, em que, do não-lugar inerente à fala suburbana da cidade do Rio de Janeiro, emerge a voz do compositor que foi ativo na construção da história nacional, subiu morros, desceu-os, falou por degredados e desvalidos, deu-lhes voz e enuncia continuamente há quatro décadas de seu lugar de arauto.

A letra de "Subúrbio" representa o cotidiano dos marginalizados do Rio de Janeiro - metáfora de Brasil- em oposição à vida dos bairros privilegiados da cidade. As estratégias de representação são diversificadas ressaltando as diferenças pelo opositivo 'lá', lugar das carências x 'aqui', lugar de fala do enunciador e da cidade que 'abusa de ser tão maravilhosa'! O eu poético conclama a reação dos desvalidos suburbanos pela valorização da arte localmente produzida quando provoca:"Vai, faz ouvir os acordes do choro-canção/Traz as cabrochas e a roda de samba/Dança teu funk, o rock, forró, pagode, reggae/Teu hip-hop/Fala na língua do rap/Desbanca a outra” justamente e repetindo... "A tal que abusa/De ser tão maravilhosa".

A metáfora do 'labirinto', 'avesso da montanha', cuja frente seria a Zona sul da cidade, a do lugar das praias, vai ser central nessa construção de sentido. Remete ao sem saída aparente dos inúmeros problemas que enfrentam os que estão na base da escala social urbana. A sequência de imagens antitéticas (positivo x negativo), algumas em destaque abaixo com grifos nossos, propicia a reiteração dos campos semânticos ligados à "pobreza" com os quais se constroem as isotopias espaciais, actanciais e temporais com a enumeração nominativa dos subúrbios. Essa enumeração vem precedida do chamamento instigador "Fala"! E não sem intenção, certamente o último potente verso é 'Fala, Paciência!'”.

\author{
Lá não tem brisa \\ Não tem verde-azuis \\ Não tem frescura nem atrevimento \\ Lá não figura no mapa \\ No avesso da montanha, é labirinto \\ É contra-senha, é cara a tapa \\ Fala, Penha \\ Fala, Irajá \\ Fala, Olaria \\ Fala, Acari, Vigário Geral \\ Fala, Piedade \\ Casas sem cor \\ Ruas de pó, cidade \\ Que não se pinta \\ Que é sem vaidade
}


Vai, faz ouvir os acordes do choro-canção

Traz as cabrochas e a roda de samba

Dança teu funk, o rock, forró, pagode, reggae

Teu hip-hop

Fala na língua do rap

Desbanca a outra

A tal que abusa

De ser tão maravilhosa

Lá não tem moças douradas

Expostas, andam nus

Pelas quebradas teus exus

Não tem turistas

Não sai foto nas revistas

Lá tem Jesus

E está de costas

Fala, Maré

Fala, Madureira

Fala, Pavuna

Fala, Inhaúma

Cordovil, Pilares

Espalha a tua voz

Nos arredores

Carrega a tua cruz

E os teus tambores

Vai, faz ouvir os acordes do choro-canção

Traz as cabrochas e a roda de samba

Dança teu funk, o rock, forró, pagode

Teu hip-hop

Fala na língua do rap

Fala no pé

Dá uma idéia

Naquela que te sombreia

Lá não tem claro-escuro

A luz é dura

A chapa é quente

Que futuro tem

Aquela gente toda

Perdido em ti

Eu ando em roda

É pau, é pedra

É fim de linha

É lenha, é fogo, é foda 


\author{
Fala, Penha \\ Fala, Irajá \\ Fala, Encantado, Bangu \\ Fala, Realengo... \\ Fala, Maré \\ Fala, Madureira \\ Fala, Meriti, Nova Iguaçu \\ Fala, Paciência...
}

A importância dos compositores que, como Chico Buarque, desenvolveram um projeto artístico projetado a partir de uma observação crítica contínua do real - como demonstra a letra que acabamos de comentar é sustentar no público uma conexão com sua própria emoção diante da obra e fazer ressoar seus sentidos. É nesse instante de encontro do eu poético com o seu leitor-ouvinte que forças desconhecidas se cruzam, dialogam, e é possível também criar-se uma tensão extremamente rica entre o produto artístico e a teoria (ou a sua visão crítica), convergente para a compreensão dos valores éticos, sociais e culturais que nos envolvem.

Naturalmente, o que propomos aqui é uma leitura conjetural, que visa oferecer uma possível abertura de entendimento dos anseios das vozes que transpiram nos versos, ampliadas pelo dono textual da voz. No processo de semiose ilimitada é possível passarmos de um nó qualquer a outro nó, mas as passagens são controladas por regras de conexão que a nossa história cultural de algum modo legitimou, como nos ensina Eco (1995), e é dessa forma que queremos essa reflexão.

A conclusão a que me permito chegar e expôr é que, diante do vasto repertório de estilos que hoje configuram a canção brasileira, cada um deles representa o sujeito que vive, sente e pensa sua realidade a partir de seus contextuais. Os estudos literários, hoje, manifestam-se pela abertura de processos que compreendem o encadeamento sistematizado das várias esferas que circundam o ser na expressão de sua existência.

Teorias excludentes não se sustentam. Nesta primeira década do século XXI, o pensamento analítico incorporou o olhar voltado para a diferença e para as manifestações das pluralidades, propiciando a compreensão da riqueza dos híbridos artísticos. Descartamos para fins de estudo literário canções que sejam meras reprodutoras de clichês, homogeneizadoras de pensamento ou reprodutoras de distorções sociais criminosas, como são as letras de muitos funks cariocas ou dos raps do estilo Gangsta (a designação Gangsta é um derivativo de gangster e as letras veiculam conteúdos incitadores de ações violentas, com palavras de baixo calão) adotadas em certos redutos no Brasil. Tais produtos caberão melhor, para efeito de estudo, na área da Sociologia, consideramos.

A expressão artística relativizou-se como um lugar privilegiado daquele que performatiza, ou seja, dá voz estetizada a suas pulsões de vida e morte. No caso das canções, funcionam como fronteiras intersubjetivas de compreensão do mundo em que vivemos. Após o processo de desconstrução e desreferencialização do real, propiciado pelas fraturas a que o século XX foi submetido, como a econômica, a estética e a 
cultural como nos dizem Lipovetsky e Serroy (2011), o olhar crítico analítico busca investigar na matéria poética -lugar de confluência dos símbolos da cultura- a rehistorização do eu, e do outro face à aceleração e à compressão do tempo-espaço que o faz deslizar na fluidez dos laços relacionais.

Mas, é justamente dentro da cultura-mundo, repleta de nuances criativas, que o ser e suas relações têm a existência valorizada. A canção popular brasileira, como manifestação artística de massa e por sua natureza intersubjetiva,- reorganiza paixões propiciando aos protagonistas -autores e leitores-ouvintes- conexões identitárias. A pluralidade de que se investiu nas últimas décadas expõe justamente o paradoxo qualitativo deste gênero híbrido, o que instiga à continuidade das pesquisas sobre sua importância representativa após mais de um século de existência, na configuração dos sujeitos culturais que somos.

\section{REFERÊNCIAS}

BAUMAN. Zigmunt. Amor líquido. Rio de Janeiro: Jorge Zahar Editor. 2004.

BHABHA, Homi. O local da cultura. Minas Gerais: Editora da UFMG, 1998.

CERRADOS. Poesia brasileira contemporânea. Brasília: Programa de Pós-graduação em Literatura, UnB. Número 18. Ano 13, 2004.

CYNTRAO, Sylvia, H. Como ler o texto poético: caminhos contemporâneos. Brasília: Plano Editora, 2004.

, Sylvia H. (org.) Poesia: o lugar do contemporâneo. Brasília: Departamento de Teoria literária e Literaturas/UnB, 2009.

DAPIEVE, BRock: o rock brasileiro dos anos 80. Editora 34, RJ, 1996.

, Sylvia H. O que será que me dá, o que será que lhe dá, o que será que dá dentro da gente? In FERNANDES, Rinaldo (org.) Chico Buarque, o poeta das mulheres, dos desvalidos e dos perseguidos. S. P: Leya: 2013.

ECO, Umberto. Os limites da interpretação. SP. Perspectiva, 1995.

ELIADE, Mircea. Imagens e símbolos. São Paulo: Martins fontes, 1991.

ELIAS, Norbert. O processo civilizador - Volume 1: Uma História dos Costumes.

Trad. Ruy Jungmann. Rio de Janeiro: Jorge Zahar, 1994. 2v.

GIDDENS, ANTHONY. A transformação da intimidade. SP: UNESP, 1993.

HALL, Stuart. A identidade cultural na pós-modernidade. Rio de Janeiro. DP\&A, 1998.

HOBSBAWN, Eric. Era dos extremos o breve século XX 1914-1991. São Paulo: Companhia das Letras, 1995.

HOLLANDA, Francisco Buarque. Subúrbio. In: Carioca. Maus, Sarapui Produções Artísticas, (p) 2006. $1 \mathrm{CD}(56 \mathrm{~min} 59 \mathrm{~s})$. (Cmpct Disc).

JOBIM, J.Luís.et alli. Lugares dos discursos literários e culturais. Rio de Janeiro: EdUFF, 2006.

LIPOVETSKY, Gilles. A felicidade paradoxal. Ensaio sobre a sociedade do hiperconsumo. Lisboa: Edições 702007.

LIPOVETSKY, Gilles. Os tempos hipermodernos. Trad. Mário Vilela. São Paulo: Editora Barcarolla, 2004.

LIPOVETSKY, Gilles. A sociedade da decepção. Trad. Armando Braio Ara. Barueri, SP: Manole, 2007. LIPOVETSKY, Gilles; SERROY, Jean. A cultura-mundo: resposta a uma sociedade desorientada. Tradução Maria Lúcia Machado. São Paulo: Companhia das Letras, 2011.

MAINGUENEAU, Dominique.Termos-chave da Análise do discurso. Belo Horizonte: Editora UFMG, 1998. 
SILVA, Anazildo V. Quem canta comigo: a representação do social em Chico Buarque. RJ: Garamond, 2013.

ZUMTHOR, Paul. Performance, recepção, leitura. Tradução: Jerusa Pires Ferreira e Suely Fenerich. São Paulo: Cosac Naify, 2007.

Recebido em: 18/02/2014. Aprovado em 15/06/2014.

Title: Redefining the place of MPB in contemporary Brazilian culture Author: Sylvia H. Cyntrão

Abstract: This text aims to discuss certain aspects of Brazilian popular song from the early $20 \mathrm{TH}$ century 60 years and how it manifests itself at the same time as aesthetic representation vector-a cultural product that works with the Transfiguration of reality, manipulating a collective symbolic capital.This article tries to offer some clues about the social and existential place of songwriter today, in Brazil.

Keywords: Culture. Imaginary. Contemporary poetry. 